\title{
Pengaruh Pelayanan Dan Fasilitas Terhadap Kepuasan Pengunjung Dunia Air Tawar Taman Mini Indonesia Indah
}

\author{
Sugeng Santoso, Asim \\ Universitas Respati Indonesia \\ sugengsantos36@gmail.com,acim_madu1@yahoo.com
}

\begin{abstract}
ABSTRAK
Penelitian ini berjudul Pengaruh Pelayanan (X1),Dan Fasilitas (X2) Terhadap Kepuasan Pengunjung Dunia Air Tawar Taman Mini Indonesia Indah (Y). Penelitian ini adalah untuk mengungkapkan indikator pengaruh Pelayanan yaitu variable X1, Fasilitas variable X2 Dan variable Kepuasan Pengunjung Dunia Air Tawar Taman Mini Indonesia Indah sebagai variable Y.Lokasi penelitian berada di Taman Mini Indonesia Indah, Jakarta. Tehnik pengambilan sampel adalah sensus, yaitu mengumpulkan data dari seluruh elemen dalam instrumen utama untuk mengumpulkan data primer. Analisis penelitian menggunakan SPSS.Temuan penelitian ini adalah 1) Pengaruh Pelayanan berpengaruh terhadap Kepuasan Pengunjung, 2) Fasilitas berpengaruh Terhadap Kepuasan Pengunjung. Penelitian ini termasuk paradigma penelitian kuantitatif dengan menggunakan metode survei di lapangan dan di landasi teori yang populasinya adalah pengunjung Dunia Air Tawar Taman Mini Indonesia Indah dengan berjumlah 100 denganmenggunakan metode accidental sampling.Untuk mencapai kepuasan pengunjung Dunia Air Tawar -TMII, maka Dunia Air Tawar-TMII harus selalu meningkatkan kualitas pelayanan dan memelihara dan memperbaharui fasilitas-fasilitas yang ada di Dunia Air Tawar-TMII agar pengunjung yang berkunjung ke Dunia Air tawar mendapatkan kepuasan saat berkunjung.
\end{abstract}

Kata Kunci : Pelayanan,Fasilitas dan Kepuasan Pengunjung 


\section{ABSTRACT}

This study entitle effect the influence $\left(X_{1}\right)$ and facilties $\left(X_{1}\right)$ satisfaction of visitors freshwater world-TMII $(Y)$. This research is to revealindicators of the effect of service is the variable. The research location is in the Mini Park of Indonesia Indah, Jakarta. Sampling technique is a census, which is colleting data from all elements in main instrument to collect primary data. Research analysis uses SPSS. This findings of this study are 1), service effects visitor satisfaction. 2) Facilities affect visitor satisfaction. This study included quantitative research paradigm using survey method in the field and based on the theory that population is the visitors to the fresh water world the beautiful Indonesian with sample of 100 using the accindental sampling method.To achieve the satisfaction of TMII's Freshwater World visitors, then the world of Freshwater TMII must always improve the quality of service and maintain and renew existing facilities in the World of the Freshwater TMII so that visitors who visit the World of Freshwater get satisfaction when visiting.

Keyword : Influence of Service, Facilities and Satisfaction of Visitors

\section{PENDAHULUAN}

Pariwisata adalah salah satu sektor penggerak ekonomi yang menjadi solusi pemerintah dalam meningkatkan pembangunan ekonomi. Sektor pariwisata tidak hanya menyentuh sektor - sektor ekonomi tertentu tetapi dapat menjangkau kalangan bawah, masyarakat di lingkungan sekitar objek-objek wisata dapat mendirikan kegiatan-kegiatan ekonomi, misalnya mendirikan penginapan, layanan jasa, warung dan lain - lain. Kegiatan kegiatan ini dapat menambah pendapatan masyarakat dan dapat menekan angka pengangguran.

Dunia Air Tawar adalah salah satu objek wisata yang berada di dalam Taman Mini Indonesia Indah. Dunia Air Tawar - TMII terletak di sebelah selatan kawasan Taman Mini Indonesia Indah, di apit oleh Museum Serangga dan Taman Legenda Keong Emas, Dunia Air Tawar -
TMII adalah sarana rekreasi yang menyajikan koleksi yang bertemakan "Indonesia Dan Dunia Air Tawar". Dunia Air Tawar-TMII di bangun di atas area seluas $5500 \mathrm{~m} 2$ di tepi danau buatan yang menyatu membentuk lingkaran air tawar. Dunia Air Tawar - TMIl di resmikan tanggal 20 April 1994 oleh Presiden Republik Indonesia Bapak Soeharto. Tujuan di dirikannya Dunia Air Tawar Ini yaitu sebagai tempat objek wisata, sebagai tempat konservasi bagi biota air tawar, sebagai tempat edukasi untuk pelajar, mahasiswa dan juga masyarakat serta sebagai tempat penelitian biota air tawar. Dunia Air Tawar - TMII merupakan taman terbesar dan terlengkap kedua di dunia dan terbesar di Asia, menyimpan kurang lebih 6000 ekor, 165 spesies terdiri dari berbagai jenis, ukuran dan asalnya baik Itu berasal dari perairan Indonesia maupun dari perairan belahan dunia lain meliputi : tanaman air, reptile, crustacean dan 
ikan. Dunia Air Tawar-TMII juga dilengkapi fasilitas lain seperti, perpustakaan, akuarium nusantara, bioskop 3D, karantina, pelatihan, mushola dan lahan parkir yang luas kesemua merupakan daya tarik tersendiri untuk di nikmati dan di pelajari penyajiannya, ini bertujuan untuk memenuhi fungsi dari Dunia Air

\section{METODE}

Penelitian ini termasuk paradigma penelitian kuantitatif dengan menggunakan metode survei lapangan dan di dasari landasan teori yang berusaha untuk melakukan pengukuran terhadap apa yang dilakukan di lapangan, di samping itu penelitian ini juga termasuk penelitian korelasional, karena ingin mengukur berpabesar pengaruh antara variable bebas denganj variable terkait, variable dimaksud adalah varable kepuasan pengunjung (Y). sebagai variable terikat dan variable pelayanan $\left(X_{1}\right)$ serta fasilitas $\left(X_{2}\right)$ sebagai variable bebas,

Tabel 4.2.

Karakteristik Responden ( $\mathrm{N}=100)$ Berdasarkan Jenis Kelamin

Jenis_Kelamin

\begin{tabular}{|l|r|r|r|r|}
\hline & $\begin{array}{r}\text { Frequen } \\
\text { cy }\end{array}$ & Percent & $\begin{array}{c}\text { Valid } \\
\text { Percent }\end{array}$ & \multicolumn{1}{c|}{$\begin{array}{c}\text { Cumulative } \\
\text { Percent }\end{array}$} \\
\hline Laki-laki & 41 & 41,0 & 41,0 & 41,0 \\
$\begin{array}{l}\text { Perempua } \\
\mathrm{n}\end{array}$ & 59 & 59,0 & 59,0 & 100,0 \\
Total & 100 & 100,0 & 100,0 & \\
\hline
\end{tabular}

Tawar - TMII sebagai wahana rekreasi yang sehat dan inspiratif bagi seluruh keluarga, wahana edukasi bagi pelajar, mahasiswa dan juga bagi masyarakat serta sebagai wahana konservasi.

\section{HASIL}

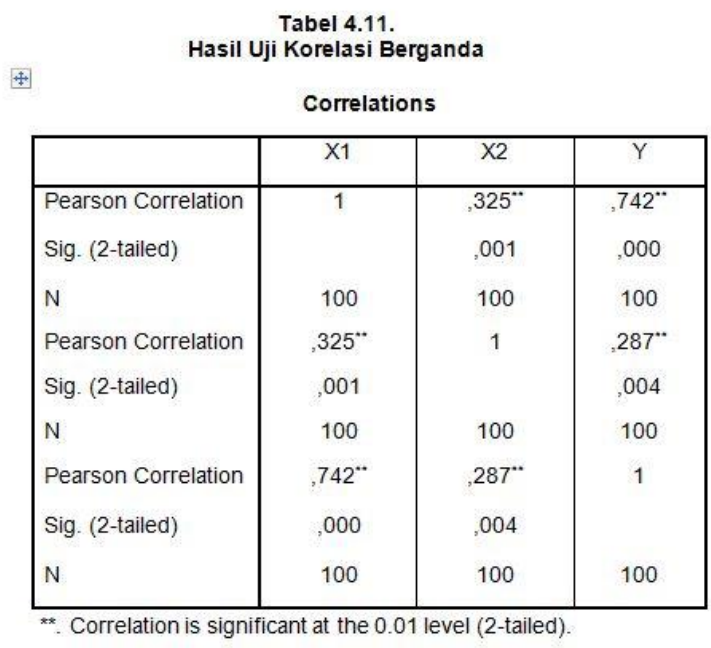

Berdasarkan tabel di atas diperoleh hasil sebagai berikut:

1) Korelasi antara variabel Pelayanan dengan Kepuasan Pengunjung diperoleh nilai $r=0,415$, dengan probabilitas $0,003<0,05$ nilai ini menunjukan adanya pengaruh sedang antara Pelayanan dengan Kepuasan Pengunjung, artinya bahwa 41,5\% Kepuasan Pengunjung berpengaruh dengan Pelayanan.

2) Korelasi antara variabel Fasilitas dengan Kepuasan Pengunjung diperoleh nilai $r=0,643$, dengan probabilitas $0,000<0,05$ nilai ini menunjukan adanya pengaruh yang kuat antara Pelayanan dengan Kepuasan Konsumen, artinya bahwa 64,3\% Kepuasan Pengunjung berpengaruh dengan Fasilitas.

3) Korelasi antara variabel Pelayanan, Fasilitas dan Kepuasan Pengunjung 
diperoleh sebesar 0,659 atau $65,9 \%$, artinya antara ketiga variabel tersebut memiliki pengaruh yang kuat. Hasil uji korelasi berganda dapat dilihat pada nilai $R$ dalam tabel Summary.

\begin{tabular}{l} 
Tabel 4.12. \\
Hasil Uji Determinasi \\
Model Summary \\
\begin{tabular}{|l|c|c|r|r|}
\hline $\begin{array}{l}\text { Mod } \\
\text { el }\end{array}$ & $R$ & $\begin{array}{c}\text { R } \\
\text { Square }\end{array}$ & $\begin{array}{c}\text { Adjusted R } \\
\text { Square }\end{array}$ & $\begin{array}{c}\text { Std. Error of } \\
\text { the Estimate }\end{array}$ \\
\hline 1 &, $743^{a}$ &, 552 &, 543 & 2,40189 \\
\hline
\end{tabular} \\
\hline
\end{tabular}

Table di atas membuktikan nilai adjusted $\mathrm{R}$ Square sebesar 0,543 yang artinya variable bebas mampu menjelaskan sebesar $54,3 \%$ variasi terikat sedangkan sisanya $45,7 \%$ di jelaskan oleh variable lain di luar variable bebas.

Nilai korelasi $R$ sebesar 0,743 menunjukan bahwa hubungan antara variable bebas terhadap variable terikat sangat kuat.

Tabel 4.14.

Hasil Uji Koefisien Regresi Secara Simultan (Uji F)

ANOVA $^{\text {a }}$

\begin{tabular}{|c|c|c|c|c|c|c|}
\hline \multicolumn{2}{|c|}{ Model } & $\begin{array}{l}\text { Sum of } \\
\text { Squares }\end{array}$ & Df & $\begin{array}{c}\text { Mean } \\
\text { Square }\end{array}$ & $\mathrm{F}$ & Sig. \\
\hline \multirow{3}{*}{1} & $\begin{array}{l}\text { Regressio } \\
\mathrm{n}\end{array}$ & 690,039 & 2 & 345,020 & 59,805 &, $000^{b}$ \\
\hline & Residual & 559,601 & 97 & 5,769 & & \\
\hline & Total & 1249,640 & 99 & & & \\
\hline
\end{tabular}

a. Dependent Variable: $Y$

b. Predictors: (Constant), X2, X1

Berdasarkan hasil diatas di peroleh $\mathrm{F}$ hitung sebesar 59,805. Dengan menggunakan tingkat keyakinan $95 \%$, alpha $(\alpha)=5 \%$. Derajat kebebasan pembilang sebesar $(k-1)$ atau (3-1)=2 dan derajat kebebasan penyebut ( $n-k)$ atau $100-$ $3=97$ ( $n$ adalah jumlah data dan $k$ adalah jumlah variable), maka di peroleh 3,09. Hal menunjukan bahwa model yang di gunakan untuk menjelaskan pengaruh Pelayanan, Fasilitas terhadap Kepuasan Pengunjung Dunia Air Tawar-TMII dapat di terima.

\section{Kesimpulan}

Berdasarkan hasil penelitian dan pembahasan mengenai Pengaruh Pelayanan dan Fasilitas terhadap Kepuasan Pengunjung Pada Dunia Air Tawar-TMII, maka penulis dapat menarik beberapa kesimpulan debagai berikut:

1. Berdasarkan hasil uji korelasi antara variabel Pelayanan $\left(\mathrm{X}_{1}\right)$ dengan Kepuasan Pengunjung $(\mathrm{Y})$ menunjukkan adanya pengaruh sedang antara Pelayanan dengan Kepuasan Pengunjung, artinya Kepuasan Pengunjung dipengaruhi oleh Pelayanan sedangkan sisanya dipengaruhi atau dijelaskan oleh variabel lain yang tidak dimasukkan dalam model penelitian ini.

2. Berdasarkan hasil uji korelasi antara variabel Fasilitas $\left(\mathrm{X}_{2}\right)$ dengan Kepuasan Pengunjung $(\mathrm{Y})$ ini menunjukan adanya pengaruh yang kuat antara Pelayanan dengan Kepuasan Pengunjung, artinya bahwa Kepuasan Pengunjung dipengaruhi oleh Fasilitas sedangkan sisanya dipengaruhi atau dijelaskan oleh variabel lain yang tidak dimasukkan dalam model penelitian ini.

Pelayanan $\left(X_{1}\right)$ dan Fasilitas $\left(X_{2}\right)$ berpengaruh terhadap Kepuasan Pengunjung. 


\section{DAFTAR PUSTAKA}

[1] Tjiptono 2010, skripsi Pengaruh Kualitas dan Fasilitas Rumah Sakit Terhadap Kepuasan Konsumen.Rumah Sakit Karitas Sumba Barat daya ,Universitas Sanata Dharma Yogjakarta, 2018.

[2] Kotler Dan Keller Dalam Buku Fandy Tjiptono 2014, Skripsi Pengaruh Kualitas Pelayanan dan Fasilitas Rumah Sakit Terhadap Kepuasan Konsumen Rumah Sakit Karitas Sumba Barat Daya, Universitas Sanata Dharma Yogyakarta, 2018.

[3] Chandra, Gregorius dan Fandy Tjiptono Ph.D. 2012. Pemasaran Strategik. Yogyakarta : CV Andi

[4] Haryanto, Edy. 2013. Kualitas Layanan, Fasilitas dan Harga Pengaruhnya Terhadap Kepuasan Pengguna jasa LayananPada Kantor SAMSAT Manado. Jurnal EMBA, Vol,. Manado :Universitas Sam Ratulangi Manado (1-11)

[5] Kotler dan Keller. 2016. Marketing Managemet, $15^{\text {th }}$ edition. United States : Pearson Education.

[6] Lupiyoadi, Rambat. 2013. Edisi ke 3. Manajemen Pemasaran Jasa, Jakarta : Berbasis Kompetensi. Jakarta : Salemba Empat.

[7] Lovelock, Christpher dan Lauren K. Wright.2007.manajemen Pemasaran Jasa, Jakarta : PT Macanan Jaya Cemerlang
Layanan Terhadap Kepuasan Pelanggan Pada SPBU Pertamina 54.612.64 di Sidoarjo.Jurnal IImu \& Riset Manajemen, Vol. 3,No. 8 Surabaya : Sekolah Tinggi IImu Ekonomi (STIESIA)

[9] Momgkaren, Steffi. 2013. Fasilitas dan Kualitas Pelayanan \{Pengaruhnya Terhadap Kepuasan Pengguna Rumah Sakit Advent Manado. Jurnal EMBA vol. 1. No, 4. Manado : Universitas Sam Ratulangi Manado.(1-11)

[10] Putranto, Thomas Aquinas Wahyu Adi, 2011, Skripsi : Pengaruh Kualitas Pelayanan dan Fasilitas terhadap kepuaasan konsumen (study kasus pada Kereta api Indonesia Daerah Operasional Yogyakarta : Universitas Sanata Dharma.

[11] Sabarguna,Dr,dr H, Boy S 2008 Quality assurance Pelayanan Rumah Sakit Jakarta . CV. Sagung Seto.

[12] Smaradhana, Sekar Nurmalita. 2017 Pengaruh Kualitas Layanan dan Fasilitas Fisik Terhadap Kepuasan Pelanggan.di The 101 Hotel Bandung Dago. Jurnal eproceeding of Apllied Science, Vol, No,3, No, 2 Bandung : Universitas Telkom.

[13] Singaburn dan Effendy, 1997:163, Pengaruh Promosi dan Kualitas Pelayanan Terhadap Peningkatan Jumlah Pengunjung Dunia Air Tawar-TMII

[8] Martoatmodjo, Soebari. 2014. Pengaruh Fasilitas dan Kualitas 